\title{
A centralidade de Paulo Freire para uma Educação pública, democrática e participativa: entrevista com Licínio C. Lima ${ }^{1}$
}

\section{The centrality of Paulo Freire for public, democratic, participatory Education: an interview with Licínio C. Lima}

\author{
Ruth Pavan* \\ Licínio C. Lima**
}

\begin{abstract}
RESUMO
A presente entrevista com o professor Licínio C. Lima, pesquisador e professor do Instituto de Educação da Universidade do Minho (Portugal), tem como objetivo explicitar as contribuições de Paulo Freire para o campo da Educação, com destaque para os estudos sobre educação ao longo da vida, autonomia das escolas, gestão democrática e formação de professores, entre outros.
\end{abstract}

Palavras-chave: Paulo Freire. Educação democrática. Autonomia escolar.

\begin{abstract}
This interview with Licínio C. Lima, a researcher and professor from the Institute of Education of Minho University (Portugal), aims to evidence the contributions of Paulo Freire to the field of Education, with an emphasis on the studies on lifelong education, school autonomy, democratic management and teacher education, among others.
\end{abstract}

Keywords: Paulo Freire. Democratic education. School autonomy.

1 A pesquisa recebeu financiamento da Fundação de Apoio ao Desenvolvimento do Ensino, Ciência e Tecnologia do Estado do Mato Grosso do Sul (FUNDECT).

* Universidade Católica Dom Bosco. Campo Grande, Mato Grosso do Sul, Brasil. E-mail: ruth@ucdb.br - http://orcid.org/0000-0001-8979-1125

** Instituto de Educação da Universidade do Minho. Braga, Portugal. E-mail: 1lima@ ie.uminho.pt - http://orcid.org/0000-0003-0899-7987 


\section{Apresentação}

Licínio Carlos Viana da Silva Lima, ou professor Licínio C. Lima, é conhecido no Brasil por suas obras na área da Administração Educacional, pelas inúmeras palestras que proferiu em diferentes universidades e eventos na área da Educação e, principalmente, por suas contribuições no aprofundamento e na articulação que estabelece com o pensamento de Paulo Freire. Sua densa discussão teórica ratifica a absoluta atualidade e pertinência do pensamento de Paulo Freire para uma educação radicalmente democrática, portanto, na contramão das políticas educacionais vigentes, que seguem a lógica mercantil.

Licínio C. Lima é professor catedrático do Departamento de Ciências Sociais da Educação do Instituto de Educação da Universidade do Minho (Braga, Portugal). Coordena diversos projetos de investigação, de formação e de cooperação de âmbito nacional e internacional. É autor de inúmeros trabalhos acadêmicos, publicados em diferentes países europeus e do continente americano.

Pertence à European Society for Research on the Education of Adults (ESREA), tendo sido membro de sua direção. É membro e sócio-fundador da Sociedade Portuguesa de Ciências da Educação, do Fórum Português de Administração Educacional e do Instituto Paulo Freire de Portugal. De sua extensa obra bibliográfica, amplamente conhecida no Brasil, destacamos: Organização escolar e democracia radical: Paulo Freire e a governação democrática da escola pública; Aprender para ganhar, conhecer para competir: sobre a subordinação da educação na "sociedade da aprendizagem"; Educação ao longo da vida: entre a mão direita e a mão esquerda de Miró; A escola como organização educativa: uma abordagem sociológica.

A entrevista, realizada presencialmente na Universidade do Minho em novembro de 2017, foi gravada e transcrita na íntegra durante os estudos de pósdoutoramento em Educação, supervisionados pelo professor Licínio C. Lima.

A seguir, a entrevista com o professor.

Ruth Pavan: Paulo Freire é um pensador citado e lembrado de forma recorrente em seus escritos. Inicialmente, essa sua aproximação com o autor se deu mais pelo caminho da educação de jovens e adultos, pela administração educacional ou por outros caminhos?

Licínio C. Lima: Diria que foi um pouco de tudo, porque, na verdade, os meus primeiros contatos com a obra de Paulo Freire foram iniciados em 1976, na minha formação de graduação, num contexto de estudo das correntes 
contemporâneas da Pedagogia; num contexto, eu diria, marcado pela Filosofia da Educação, pelas correntes pedagógicas. Paulo Freire era introduzido como um marco importante no pensamento educacional, com diversos impactos, mas não era apropriado de uma forma específica em termos de educação de adultos ou de outra área qualquer.

Nós estudávamos as correntes da pedagogia e quando se chegava ao século XX Paulo Freire aparecia. As ideias que eu tenho desse tempo de formação é que nós líamos alguns trechos da Pedagogia do oprimido e da Educação como prática de liberdade. Ficávamos com esse conhecimento genérico.

$\mathrm{Na}$ verdade, só começo a estudar Paulo Freire de uma forma mais sistemática, para além da educação de adultos, redescobrindo as questões da política educacional da administração ou gestão educacional, quando o meu colega Almerindo Afonso vai ao Brasil nos anos de 1990, aí por meados de 1995, 1996. Como ele sabia do meu interesse por Paulo Freire, me traz uma obra que foi realmente marcante para mim, que é a Educação na cidade, um conjunto de entrevistas que Paulo Freire dá a propósito de sua ação na Secretaria Municipal de Educação de São Paulo.

Eu releio Freire e encontro preocupações comuns, que tinham sido já nossas preocupações - a questão da autonomia da escola, a questão da participação na escola, a democracia, a participação no processo de decisão; nós insistíamos muito em que a direção da escola, que era um órgão político, tinha que ter poder de decisão. A conexão da escola com a comunidade, com os pais e as mães, digamos, os vários setores sociais, a abertura à comunidade.

Foi realmente surpreendente. Creio que pouca gente em Portugal tinha acompanhado o regresso de Freire ao Brasil depois do exílio. Portanto, nós nos fixávamos um pouco nas grandes obras de Freire, basicamente dos anos de 1970, e não acompanhávamos, não conhecíamos todo o trabalho que ele foi produzindo, sobretudo após o seu regresso ao Brasil. Esse livro entusiasma-me muito porque, no fundo, há uma coincidência de ideias muito grande, há a descoberta de que Freire não é só educação de adultos, alfabetização, etc.

Isso me leva a dar muita atenção à Educação na cidade e, a partir daí, procurar, sistematicamente, não apenas reler as obras que eu tinha lido como estudante, na juventude, mas relê-las com outra visão, com outra maturidade, com outros interesses mais alargados, mas também fazer um programa sistemático de leituras de Paulo Freire. Em 1997, para mim, é claro o interesse que Paulo Freire tem nessa dimensão global, não apenas na educação de adultos, mas nas questões mais genéricas da democracia, da participação, da gestão educacional, da autonomia da escola, etc.

Dediquei um ano sabático, compreendido entre setembro de 1997 e setembro de 1998, à leitura de toda a obra de Paulo Freire - tudo que eu já 
tinha lido, ou parcialmente lido. Para isso, comprei as obras, consegui as obras, consegui coisas que não estavam acessíveis, consegui vários textos que circulavam no Brasil, até, enfim, textos em cópia. Li vários textos de Freire que nem são textos tão conhecidos. Procurei também, porque estava já a orientar estudantes brasileiros nessa altura, aqui em Portugal, entrar em contato com pessoas que estavam na Secretaria Municipal de Educação de São Paulo. Em alguns casos, eu já as conhecia; noutros casos, vim a conhecer mais tarde [pessoas] que trabalharam com Paulo Freire.

Foi um programa de trabalho que deu origem a dois artigos. O primeiro foi publicado na Revista Educação, Sociedade e Culturas, e o segundo foi publicado na Revista Inovação. Depois, dediquei-me a preparar a proposta de um livro, o primeiro livro que publiquei no Brasil, no ano 2000, e que propus à Cortez Editora e ao Instituto Paulo Freire. É um livro que é debatido por Moacir Gadotti e por vários colegas em São Paulo. Há certa surpresa no início, em primeiro lugar porque é um português a escrever sobre Freire; em segundo lugar, é um português a escrever sobre Freire e sobre um tema que não era imediatamente óbvio, sobre a organização e gestão escolar, a gestão educacional, etc.

Enfim, é o resultado de um investimento que tem dois, três anos. Durante dois, três anos fiz outras coisas certamente, mas andei muito concentrado nesse trabalho. Aí, de fato, é a questão da gestão educacional, da política educacional, das concepções da democracia em Paulo Freire, o que me atrai. Eu costumo dizer que não sou um especialista em Freire - só estudo Paulo Freire, sou um estudante de Paulo Freire. Eu estudo Paulo Freire sistematicamente há 20 anos.

Como estudo sistematicamente outros autores, isso não faz de mim um especialista, sobretudo em face de outros especialistas brasileiros, mas fora do Brasil também. A verdade é que eles me tratam hoje como especialista, mas é um problema deles, eu nunca me apresentei como especialista de Paulo Freire. Agora, o fato de eu ir escrevendo, ir contribuindo e, na verdade, os colegas acharem que as contribuições têm algum interesse, têm alguma novidade, acaba por suscitar pedidos vários.

É um autor que hoje é mais fácil de trabalhar por mim, porque tenho uma visão global de toda a obra, tenho as minhas notas. Tenho os livros todos anotados, o que significa que é mais fácil partir para novos temas que vou desenvolver e que me interessam porque tenho um conhecimento global e consolidado. É claro que Freire é sempre difícil porque, quando nós vamos à procura de um tema na sua obra, isso envolve sempre algum risco. As minhas questões nunca estão claras à partida. A minha pergunta é sempre: será que Freire tem alguma coisa a dizer sobre isso? Às vezes, tenho suspeitas de que sim. Outras vezes, não tenho tantas suspeitas. 
A minha metodologia é sempre a mesma, é percorrer a obra toda, que eu manuseio com alguma facilidade neste momento, porque conheço, porque está anotada, etc., tendo o cuidado de não cair na tentação da sobreinterpretação Freire escreveu muita coisa, é verdade, mas não escreveu sobre tudo. Penso que Freire tem um pensamento profundo e global sobre a educação, mas não pensava sobre tudo. Portanto, não vale a pena fazer esse exercício de sobreinterpretação, e eu aceito esses limites, mas aceito o desafio de admitir que, lendo a obra globalmente, é possível que o autor tenha coisas a dizer ou tenha dito coisas que estão lá e que nós podemos articular, pensar, a partir de Freire. Tenho algum cuidado, porque penso que há alguns excessos, alguns exageros, na apropriação de Paulo Freire, no sentido de querer, eventualmente, que ele dê respostas aos problemas de cada um de nós. Isso não é possível! Ele procurou dar respostas aos seus problemas, aos problemas do seu tempo. Eu creio que, desse ponto de vista, ele é um autor clássico, porque abordou alguns problemas da nossa condição humana, os dilemas da educação, as dimensões fortes e fracas do que pode a educação. É verdade que, nesse aspecto, é um autor clássico, mas não dá resposta para tudo - longe disso. Ele dá as respostas dele para os problemas que ele soube colocar, que são uns, e não são outros. É assim que trabalho com Freire.

Enfim, estudo sistematicamente o autor há 20 anos. Não sei, há colegas que acham que isso faz de mim um especialista. Tenho minhas dúvidas, mas não estou muito preocupado com isso. Sei que há muitos colegas que realmente são verdadeiros especialistas, que têm o conhecimento do detalhe da obra, da obra não apenas escrita, mas da obra feita, da obra dita, dos diálogos, etc.

Dificilmente conseguirei recuperar esse tipo de conhecimento porque não estive, não fui, não estava lá. Também considero que isso não me limita especialmente porque nós não temos que ter conhecido os autores pessoalmente, ou ter feito uma jornada de trabalho com eles, para estudá-los. É por isso que continuamos a estudar os grandes autores, os autores clássicos, que já morreram, que nós nunca conhecemos, ou que não viveram no nosso tempo, que são difíceis exatamente por isso, pois nos obrigam a estudar não apenas o pensamento e obra, mas o contexto de produção da obra, que é muito importante. Isso, em Freire, é absolutamente crucial!

Alimento muito a ideia de que cada livro de Freire é uma espécie de relatório sobre o pensado e o vivido do ponto de vista político, educativo e pedagógico. Que corresponde a momentos fortes de sua vida, de intervenção, de educação, de projetos, de viagem, de diásporas, de encontros, desencontros, quer dizer, a obra dele é muito isso. A obra vai ganhando novas matizes e novas características também com esses encontros. Encontros dele com a pedagogia crítica, com Henry Giroux, com Peter McLaren, com Michael Apple; são encontros que o influenciam e influenciam muito a pedagogia crítica. Ele foi 
muitíssimo influenciado por esses autores - sobre isso, não há dúvidas -, como foi pelo movimento sindical, e há fortes influências deste na obra também. $\mathrm{O}$ último Freire é muito influenciado pelos debates educativos que ocorrem no Brasil e em que ele procura inscrever-se, ter alguma coisa a dizer.

Há o texto e o contexto. Há o texto e as circunstâncias. O próprio autor escreve durante quase quatro décadas, o mundo mudou, Freire mudou. Freire, no início, fala muito em conscientização; o Freire final, dos últimos trabalhos, não fala muito em conscientização. Freire responde às críticas à maneira dele. É um autor muito sensível às críticas que fazem às suas obras e ao seu pensamento, ele tende a responder, tende a clarificar. Há muitos textos de Freire que são respostas diretas e, em alguns casos, indiretas aos seus críticos. Ele é muito sensível às críticas, não as rejeitando, mas incorporando-as no seu pensamento e reformulando, clarificando. Em alguns casos, aceita as críticas. Isso é curioso relativamente às feministas norte-americanas nos anos de 1970, aceitando que, de fato, havia uma visão limitada, naquele momento, da parte dele.

Ruth Pavan: Mesmo que o senhor diga que não se considera um especialista em Freire, há o reconhecimento por muitos de que o senhor é, dada a contribuição que vem dando para que o pensamento de Freire continue vivo. Inclusive, em 2001, o senhor e mais três professores criaram o Instituto Paulo Freire de Portugal (IPFP). O que impulsionou esta criação? Que desdobramentos esperavam obter? Isso se concretizou?

Licínio C. Lima: Hoje tenho uma versão dos fatos; naturalmente, pode ser que a professora Luiza Cortesão tenha outra versão, ou o professor António Teodoro tenha outra. Quer dizer, há um grupo alargado e, depois, há quatro pessoas que tomam a iniciativa e se responsabilizam mais pela questão legal, estrutural e de pensar o projeto. Realmente, juntamente com o professor Stephen Stoer, assinamos a escritura notarial em 2001. Freire morre em 1997. Nós temos consciência da importância da obra, da importância de continuar a estudar a obra. Achamos que a criação de um Instituto, de uma associação para o estudo, a formação, a divulgação do pensamento de Paulo Freire, fazia sentido em Portugal naquele momento.

Em face do momento político, não apenas português, mas global, em face da importância da obra de Freire, em face de uma coisa que já se adivinhava naquela época - que Freire ia perdendo alguma centralidade em várias áreas da educação, em várias áreas da formação de professores, que se tecnicizava, se didatizava em excesso em alguns casos... No fundo, aquilo que nos mobilizava era uma homenagem a Freire, uma homenagem típica de pessoas que estudam e pesquisam, que era construir um Instituto que tinha como primeira missão estudar, debater, divulgar o pensamento e a obra, agrupar um conjunto de textos de Freire e sobre Freire. Foi isso, basicamente. 
O Instituto tem correspondido, dentro dos nossos limites, àquilo que pensávamos. São momentos de diálogo, de debate; são momentos de discussão de obras; são momentos de realização de encontros científicos, de articulação com outros institutos no mundo. Ainda há poucos meses realizamos um curso que ocorreu no Porto, exatamente sobre o pensamento e obra de Freire. Tivemos um grupo diversificado de professores, educadores, alguns estudantes de doutoramento, colegas que realizavam pós-doutoramento. Tivemos um público diversificado, interessado em saber mais sobre esse autor; [um público] que já teria ouvido, que já teria lido qualquer coisa e queria obter uma formação mais sistemática, mais orientada. Então, acho que a vocação do Instituto é, sobretudo, essa. Há de fato um lugar para Paulo Freire, há um acervo de obras, é um autor relevante. Esse Instituto pretende simplesmente criar circunstâncias para estudar e discutir o autor, para um debate acadêmico feito de uma forma plural, a partir das mais diversas perspectivas.

Ruth Pavan: Sua preocupação com Freire também está presente em suas aulas. Recentemente, o senhor publicou um documento que contém o Programa de uma disciplina do Curso de Mestrado em Ciências da Educação, intitulada "Política e politicidade da educação: o pensamento de Paulo Freire", ministrada pelo senhor (LIMA, 2017). O próprio nome da disciplina já revela uma dimensão central do pensamento de Freire: a política que nos mostra a incapacidade de sermos neutros. Entretanto, é comum vermos frases de Paulo Freire em discursos e textos acadêmicos que ignoram essa dimensão, usando-o de forma despolitizada, o que significa dizer que retiram da sua escrita um elemento estruturante, ou seja, o caráter histórico e, principalmente, as relações de poder que ocorrem nas relações sociais que reproduzem a opressão, que são constantemente problematizadas por ele. Fazer isso é ir na contramão do tema da disciplina trabalhada pelo senhor, bem como dos seus escritos e de Freire. A que o senhor atribui essa forma de apropriação do pensamento do autor?

Licínio C. Lima: Em primeiro lugar, é verdade que há muitas apropriações do pensamento e da obra de Paulo Freire, não há dúvida. Eu diria que ela é complexa! Acho que nós corremos sempre o risco de transformar Freire numa bandeira, num slogan a favor ou contra. Isso não ocorre apenas no Brasil, mas ocorre muito insistentemente no Brasil. Quer dizer, uma institucionalização exagerada de Freire, que passa a ser uma instituição, ele próprio, absolutamente contrária à obra dele, que é uma obra crítica, aguçada, provocatória, tensa, dialética, que se faz a partir do apelo do autor à própria discussão do seu pensamento. $\mathrm{O}$ autor nunca apela exatamente a que concordem com ele ou o sigam. Não! Antes a que o estudem e critiquem.

A apropriação muito simbólica, muito institucionalizada, transforma Freire num monumento, numa instituição, numa coisa rígida, numa codificação 
restrita, baseada numa hermenêutica muito específica, muito particular, eventualmente realizada por hermeneutas autorizados. Isto é, do meu ponto de vista, extremamente perigoso. Sou absolutamente contra esta perspectiva. Paulo Freire merece um estudo profundo, crítico, não condescendente, em que, mesmo quando da nossa parte há uma adesão ao conjunto de valores, a uma dimensão axiológica, a uma dimensão política, etc., isso não nos dispensa de ler, de interpretar, de criticar, de tecer diálogos com as nossas agendas, com o nosso tempo, com vários autores, com várias perspectivas.

Portanto, não existe um Paulo Freire cristalizado. Não existe uma hermenêutica freiriana única. Não existem hermeneutas autorizados porque foram seus discípulos, porque viveram com ele, trabalharam com ele ou escreveram há 30 ou 40 anos sobre ele. Freire está aí para quem quiser ler! Possivelmente, os maiores especialistas de Freire ainda estarão por vir, talvez estejam até para nascer, nunca se sabe. Se realmente o autor for um autor clássico no nosso campo, eu espero que as grandes leituras de Freire ainda estejam por vir, que são embates, diálogos, confrontos, procuras. Desse ponto de vista, creio que é assim que Freire deve ser estudado. Outra vertente, que também me parece uma vertente, enfim, com inconvenientes graves, é a didatização, ou a tecnicização de Paulo Freire. O próprio autor recusou essa perspectiva. $\mathrm{O}$ autor não estava muito confortável, mesmo com a ideia de um método Paulo Freire da alfabetização. Ele realmente nunca gostou de ver reduzido seu trabalho a um método. Ele apresenta, de fato, uma teoria pedagógica e propõe uma Filosofia da Educação, tem uma mundividência política da educação, com conceitos, etc. No exercício da alfabetização, da alfabetização crítica, todas as dimensões metodológicas, e até de técnicas e didáticas, têm o seu papel. Mas elas são de menor alcance face a uma teoria, a uma Filosofia da Educação, à dimensão político-pedagógica da sua obra.

Portanto, não é nada claro para mim que o método seja uma coisa infalível, cristalizada, que hoje continue a dar certo e que deva ser seguido naquela mesma perspectiva por todos. Isso não faz muito sentido. Hoje o Brasil não é o Brasil de Angicos, de há 50 anos, e o mundo também não é. Nós hoje vivemos num mundo digital, acessível para uns e não acessível para outros, mas o mundo dominante não deixa de ser o mundo digital.

Isso significa que o exercício talvez mais difícil, mais arriscado, mas também por isso mais interessante, é o de saber, hoje, quais são os impactos do pensamento educacional freiriano em possíveis novos projetos de educação de jovens e adultos, de alfabetização crítica, que reatualizem e que sejam criativos suficientemente para que, partindo de certas premissas freirianas, de certas dimensões, ultrapassem os limites, digamos, dos métodos e das técnicas que foram historicamente construídos num determinado momento, 
num determinado tempo e espaço. Portanto, a didatização e tecnicização são perigosas, indesejáveis, do meu ponto de vista, porque reduzem uma obra plural, complexa, eventualmente a instrumentos didáticos, técnico-didáticos ou pedagógicos num sentido restrito, que dificilmente se podem adequar à complexidade dos tempos de hoje e às condições dos tempos de hoje.

A pergunta deve ser outra. O que aprendemos com o pensamento de Freire que nos possa ainda servir para nos dar pistas, possíveis caminhos para aguçar a nossa criatividade no domínio da educação de jovens e adultos, da alfabetização, da formação inicial e continuada de professores e educadores? Esse é um debate interessante. Enfim, é possível a atualidade de Freire, e são possíveis os desenvolvimentos freirianos bem ancorados no plano teórico, no plano político de Freire, mas que Freire pode nem sequer ter imaginado.

Diria que se isso acontecer no futuro isso confirmará Freire como um autor clássico; penso que ele tem condições para sê-lo e que talvez já o seja. Enfim, o tempo o dirá, mas eu creio que o autor renasce a cada leitura.

Talvez esteja na agenda, daqui a 20 ou 30 anos, a partir de um conjunto de ideias que, neste momento, não sejam as ideias maiores, nem sejam as ideiaschave que encontramos em Freire. Mas isso será a prova de que o autor continuará a inquietar-nos, continuará a interrogar-nos; de que a obra tem essa capacidade de nos permitir estabelecer diálogos com outros autores, com os problemas da contemporaneidade. Isso é tudo, menos despolitizar a obra; isso é tudo, menos cristalizar a obra; isso é o contrário de uma apropriação restrita do trabalho de Freire. Freire só sobreviverá, desse ponto de vista, como grande autor se a partir de sua obra, do seu pensamento, de suas pistas, alargarmos o seu âmbito a novos problemas, a novas questões. Se não o fizermos, ficará naturalmente sempre com um papel na história da Pedagogia, mas será um papel mais limitado no tempo, circunscrito a um determinado momento histórico, a certos conceitos. Temos exemplos, relativamente a muitos autores da história da Pedagogia, a quem vamos buscar duas ou três ideias-chave que conhecemos, mas [esses autores] não são propriamente nossos companheiros de jornada, no sentido de que nos acompanham, nos inquietam, nos dão pistas. Esse é o teste no futuro.

De qualquer maneira, penso que esta apropriação ampla, crítica, criativa, é a única coisa que pode permitir exatamente essa longevidade, essa plenitude do pensamento freiriano. Creio sinceramente que a obra contempla dimensões suficientes para que isso aconteça, mas também depende de nós. Isso depende de nós, porque neste momento o autor não pode fazer nada por isso; tudo que tinha que fazer, está feito. Portanto, depende mais da nossa capacidade de leitura, de criatividade, de interpretação. Claro, depende da riqueza da obra, e é isso, a obra é rica, mas a sua perenidade é uma coisa para discutir no futuro. 
Ruth Pavan: Uma das ideias que o senhor tem destacado durante a entrevista é a educação democrática e crítica. Isso me faz lembrar de um capítulo intitulado "Escolarizando para uma educação crítica: a reinvenção das escolas como organizações democráticas". Nesse capítulo, o senhor se refere a Paulo Freire dizendo que ele "jamais desistiu ou, sequer, prescindiu da escola e da luta pela sua democratização" (LIMA, 2005, p. 22). No mesmo texto, o senhor se refere a "práticas pedagógicas potencialmente corrosivas" (LIMA, 2005, p. 26). Como o senhor vê esta tensão atualmente entre aqueles que persistem lutando em defesa da construção e do fortalecimento das escolas públicas e sua democratização e as práticas que corroem deliberadamente esta construção?

Licínio C. Lima: Creio que essa tensão existirá sempre. Essa tensão existe no trabalho, no pensamento de Freire, e ele dá conta dessas tensões, desses problemas. O que talvez seja interessante, por exemplo, é se nós fizermos um cotejo, uma análise comparativa da obra de Freire, por exemplo, e da obra de Ivan Illich - que têm muitas semelhanças na sua potência crítica. Veremos que Freire, apesar de tudo, nunca desiste da escola. Freire acredita no possível trânsito entre a educação de adultos não escolar, não formal, e entre a educação de crianças, jovens e adultos de tipo formal. Freire acredita que o projeto de educação permanente é algo que pode levar à mudança da escola. Freire acredita que muitas lógicas de trabalho, estilos de trabalho pedagógico da educação popular de adultos, podem ser uma contribuição para a mudança de escola.

Claro que Freire faz críticas realmente contundentes, ferozes, à instituição escolar, ao modelo de escola tradicional, à pedagogia bancária, a uma organização oligárquica da escola, à burocracia escolar. Isso é muito claro. Agora, de fato, ele nunca desiste. O projeto de democratização da escola é um projeto, para ele, indispensável ao projeto mais vasto de democratização da educação e ao ideal utópico, mas ao mesmo tempo indispensável, de uma educação permanente. Uma educação permanente da qual ele fala e tem uma concepção muito específica. Portanto, Freire é um autor que não prescinde da democratização da escola pública e do processo da luta pela sua democratização.

Eu diria que aquilo que temos que aprender com Freire e com a sua obra é a importância da democratização da organização escolar, da pedagogia, da educação, da participação; da participação como ingerência, da participação verdadeira. Essa visão política da escola é indispensável, até porque a história da pedagogia nos revela o quê? Que todas as tentativas mais ou menos circunscritas, mais ou menos cirúrgicas, mais ou menos funcionalistas, de tentar mudar a escola nunca conseguiram fazê-lo em larga escala. As ideias generosas da Escola Nova dificilmente conseguiram mudar a escola pública. Deram pistas muito interessantes, mas nunca conseguiram fazê-lo. 
Freire coloca a tônica, o enfoque, naquilo que é realmente nuclear, que é a mudança da política educativa, da política escolar, da própria estrutura e organização escolar, como elemento central de uma política. Portanto, a organização escolar e suas estruturas, os seus processos de organização e de gestão, são fenômenos de poder. Freire permite ver isso. Freire, em muitos casos, antecipa até cronologicamente muitos autores da teoria organizacional crítica; aliás, não é por acaso que muitos deles citam Freire. Desse ponto de vista, nós estamos a viver tempos bastante tensos.

Hoje o discurso dominante, de certa forma, coloca a tônica na melhoria da escola, na melhoria por meio de certas técnicas, da liderança, de uma orientação para a produção de resultados, para o movimento das escolas eficazes. Nós estamos a viver o quê? Nós estamos a viver o movimento reformista, a uma escala global, que procura mimetizar as "melhores práticas", que procura programas apoiados por grandes instituições internacionais com um receituário mais ou menos genérico e até mais ou menos independente do contexto em que ocorre, que vai num sentido completamente diferente e oposto, em muitos casos, ao que Freire propõe. Tecniciza, didatiza em exagero e, portanto, fica amputado, de certa maneira, dos instrumentos da ação política, quer em termos críticos, de reflexão e de diagnóstico, quer em termos da ação e de mudança. Na verdade, vai a reboque de um conjunto de modas e de processos, a competição, avaliação externa, os rankings das escolas, os discursos meritocráticos, certa reelitização da escola pública e a introdução de um ethos competitivo na escola, entre professores, classes, alunos, resultados. Isso é uma visão que de fato é criticada por Freire e criticada por meio de alternativas.

Uma das alternativas é a da definição de um projeto político-pedagógico na escola, participando, com certa autonomia, em tensão com as próprias diretivas nacionais, estaduais, municipais... Porque é uma tensão. Certamente, não estamos a falar de uma escola independente, não é isso que ele propõe. Ele propõe, em termos de organização da escola, do currículo, da didática, da avaliação, efetivamente, uma apropriação organizacional, local, comunitária, da escola pelos que a fazem. É uma expressão que ele utiliza muito e que é absolutamente contrária a esses padrões, a essa estandardização que nós verificamos hoje nas políticas. Freire é muito difícil de praticar hoje, desse ponto de vista.

Ruth Pavan: Sim, torna-se difícil porque a formação docente também se tornou técnico-instrumental, como o senhor em recente artigo, intitulado "Sobre a educação cultural e ético-política dos professores", chama a atenção, afirmando que a "racionalidade técnico-instrumental adquiriu renovado protagonismo na formação de professores" (LIMA, 2016, p. 153), ou seja, a formação de professores enfatizou a "feição tecnicista e didatista" (LIMA, 2016, p. 151). O 
que provocou este "renovado protagonismo" na formação de professores? Que implicações isso traz em médio e longo prazo para a educação?

Licínio C. Lima: A política que caracterizei em termos largos, rápidos, enfim, que é hoje de certa forma propagada por grandes instituições internacionais e por governos nacionais, vai nesse sentido, quer dizer, o professor é um técnico. É um técnico, um técnico das qualificações e das competências. É um técnico de gestão da sala de aula. Veja a centralidade dos problemas da indisciplina, da gestão de comportamento, do bullying. Adquiriram mesmo aspectos jurídicos, aspectos jurídicos e legais e isso tomou conta da sala de aula.

Há também a questão de uma orientação resultadista, claramente competitiva, de produção de resultados, da excelência, da meritocracia, das melhores práticas. Certa competição, certa emulação, certo mimetismo dessas pretensas melhores práticas. Nesse contexto, é claro que a formação de professores está em mudança profunda, quer dizer, nós seguimos fazendo estudos de política educativa, analisando os impactos dessas agendas tecnocráticas, neoliberais, gerencialistas, economicistas, instrumentais, pensando que as instituições de formação de professores ficariam imunes a esse processo e que o próprio projeto de formação de professores e educadores, mas sobretudo de professores, ficaria incólume?

A formação de professores, em muitos países, foi se adaptando - uma formação técnica ou profissional de índole mais politécnica, no sentido estrito do termo. Menos intelectual, uma formação menos intelectual, mais ligada a métodos e técnicas, a instrumentos de gestão, ou seja, à gestão da escola, da sala de aula; uma lógica de produção de resultados, uma lógica de controle mesmo da sala de aula, de sobrevivência do professor.

$\mathrm{Na}$ verdade, nós hoje temos um perfil - em alguns casos explícito, em alguns casos implícito - de um professor como uma espécie de especialista em coaching, em treinamento, em liderança dos seus colegas e dos seus alunos. Um professor que já não seja exatamente um professor criativo, de que se falava há umas décadas, mas que seja um professor empreendedor, que é uma coisa muito diferente. Um professor capaz de sobreviver num clima competitivo, numa competição por alunos para a própria escola, que é uma das funções hoje, competir por alunos, e depois competir por resultados, mantendo certa ordem, combatendo fenômenos de disrupção, de bullying.

Portanto, um professor gestor - vários autores defendem essa perspectiva abertamente, outros não tão abertamente, mas algumas correntes falam numa espécie de neoprofissionalismo do professor. O professor é um profissional, mas um profissional que ancora os seus saberes, as suas competências, o seu perfil profissional, exatamente nessa área de um gestor das aprendizagens, de um empreendedor, de um indivíduo competitivo, de quem se espera muito 
mais uma execução criativa, é certo, mais em conformidade com as grandes orientações de política educacional do que propriamente com a capacidade de interpretação crítica das políticas, ou de participação na produção das políticas, ou de participação ativa na gestão democrática da escola.

A gestão democrática não é levada a sério, não é discutida, não é um problema. A gestão democrática das escolas já não é sequer um problema. Porque não se discute, porque ninguém está verdadeiramente interessado em discutir a democracia na escola, isso deixou de ser um problema. Discute-se realmente a disciplina na escola, o serviço público prestado pela escola, a produção de resultados, a competição, as competências, o que deve ser ensinado na escola, as pressões sobre o currículo escolar e sobre os mandatos da educação escolar, a influência das grandes empresas, dos partidos políticos, porque todos os interesses organizados têm efetivamente agendas para a educação escolar, isso é claríssimo hoje.

Portanto, a gestão democrática, por exemplo, uma categoria importante, está arredada. Isto tem consequências profundas na formação dos professores, não há dúvidas. Não quer dizer que a formação de professores seja toda igual, indiferente às escolas, às universidades, aos professores. Ela nunca é indiferente, mas eu diria que as condições estruturais e políticas, o próprio modelo de formação e os componentes de formação tornam extremamente difícil uma formação mais larga, mais crítica, mais compreensiva, mais interpretativa, mesmo naquelas áreas que nós tenderíamos há poucos anos a considerar clássicas no pensamento e na formação de um professor, tais como os contributos da Sociologia da Educação, quer da Sociologia da Reprodução, quer da Sociologia da Resistência, entre outros.

Tudo que é perspectiva crítica, que dá uma interpretação diferenciada, permite a construção de instrumentos críticos para a profissão do professor. Não quer dizer que não sejam feitos, em alguns casos, mas mesmo as instituições que o fizeram no passado e têm recursos para o fazer no presente estão limitadas pelo modelo formal de formação, pelos componentes de formação, isto é claríssimo.

Ruth Pavan: Com a ausência da discussão crítica sobre a gestão democrática, a autonomia da escola, um tema importante nos seus escritos, em que Freire tem sido central, também sofre um intenso desgaste político, modificando o seu sentido. Poderia explicitar os diferentes caminhos que este termo tem percorrido e que concepção de autonomia a articulação do seu pensamento com o de Freire produz?

Licínio C. Lima: Sim, hoje a categoria da autonomia é curiosamente uma categoria central no pensamento político sobre educação, mas ela é central em geral a partir de apropriações bastante limitadas da autonomia. A autonomia e tenho escrito muito sobre isso - de que se fala hoje muito é uma autonomia 
operacional, técnica, executiva, implementativa. É uma autonomia mais de execução do que de concepção; é uma autonomia mais técnica ou instrumental do que política. Portanto, não é verdadeiramente autonomia. Costumo dizer, em certos textos, mas sobretudo em palestras, em conferências, que é uma autonomia heterogovernada, o que é uma contradição nos termos. Ela é autonomia porque se insinua e é apresentada no discurso político como autonomia. Contratos de autonomia, reforço da autonomia da escola. Sobre esta questão, discute-se desde 1987 em Portugal. São 30 anos de reforço da autonomia. Costumo dizer, é muito discurso sobre o reforço da autonomia e muito pouco reforço da dita autonomia.

É um discurso retórico. Praticamente todos os setores políticos usam, mas não há maiores consequências do que isso. É uma autonomia heterogovernada no sentido em que tudo o que é crucial do ponto de vista político ou estratégico, do poder de decisão, acaba por ser definido centralmente pelo Ministério da Educação, que tem uma tradição centralista em Portugal. O discurso da autonomia ou fica num discurso retórico na maior parte das vezes, ou, então, traduz-se numa relação do tipo "nós definimos a política, as grandes orientações, agora as escolas serão autônomas na melhor forma de executar as políticas". É uma autonomia centrada nos métodos, nas técnicas, nos processos, em alguns meios.

Mesmo quando implica os meios e, sobretudo, recursos, salários, dinheiro, tempo, é uma autonomia extremamente condicionada, limitada, porque aí também as escolas não podem mexer, não podem alterar as regras do jogo, e nada é autorizado que tenha, por exemplo, maiores custos para o Ministério. Isso é altamente controlado. Portanto, de fato, esta autonomia é uma muito apagada, muito despolitizada, ela é mais uma técnica de gestão, de execução local das diretivas das políticas centrais. Ela é uma autonomia também utilizada muito como instrumento de desregulação e de competição.

Há coisas que passam a ser atribuídas à escola em termos de responsabilidades e encargos para que possam ser avaliadas e imputadas à escola - os resultados escolares, por exemplo. A chamada avaliação externa da escola é uma designação que não faz sentido nenhum porque se trata de uma avaliação institucional. Nós avaliamos, o sistema avalia o quê? O que é que nessa avaliação externa é imputável efetivamente à organização escolar, à sua autonomia, à sua organização e aos seus professores, e o que não seria imputável? Eu tenho para comigo que boa parte da chamada avaliação externa da escola incide realmente sobre ações, decisões, recursos e deliberações do poder central.

Nós estamos a tentar avaliar no local, na organização escolar, o impacto de certas políticas educativas que são definidas centralmente, mas que nós, depois, mediante esse processo de avaliação externa e por meio do discurso da autonomia, imputamos à escola. Quer dizer, na escola, vai se perguntar 
que políticas têm de promoção do sucesso educativo. Como é que consegue fazer planos de recuperação dos alunos que evidenciam mais dificuldades nos resultados escolares? Como é que se combate o abandono escolar? É claro que a escola, as dinâmicas escolares, as dinâmicas organizacionais, pedagógicas, têm sempre algo a dizer sobre isso. Mas num país fortemente centralizado como é o nosso, diria que a maior parte dos instrumentos de gestão pedagógica, de alteração dos processos e da própria morfologia da organização escolar, que permitiriam realmente respostas positivas a esses desafios, a essas questões, não dependem da escola.

Em boa parte, estão nas mãos do poder central. Então, quando avaliamos externamente as escolas, será que estamos a avaliar as escolas? É uma pergunta que me vem à cabeça muitas vezes. Qual é a responsabilidade da escola ou do agrupamento de escolas? Qual é a percentagem que deriva de fato da ação do poder central?

Toda gente fala da autonomia, todas as agendas políticas, todos os partidos políticos falam da autonomia da escola, querendo dizer com isso coisas bastante diferentes. Até porque os críticos dessa concepção de autonomia também falam de autonomia. Agora, é preciso realmente explicar que há vários processos, várias formas, várias concepções de autonomia e que a autonomia que uns defendem não é a autonomia que outros defendem. E onde está a diferença? É preciso demonstrar que não há qualquer consenso, nem na literatura, nem na prática pedagógica, educacional e organizacional, nem no discurso político, entre essas variadas concepções de autonomia. São concepções de autonomia completamente distintas.

Freire, desse ponto de vista, é um auxiliar extraordinário, porque Freire viu muito cedo algumas das coisas que as perspectivas críticas sobre o gerencialismo e a nova gestão pública vieram a dizer. Ele viu exatamente esse perigo de uma apropriação neoliberal, mercantil, da autonomia e é crítico relativamente a isso.

Freire dá-nos algumas pistas sobre o que é que no plano político, democrático, no aprofundamento da democracia escolar, da participação, da decisão, pode ser feito nessa vertente que podemos dizer freiriana, compatível, digamos, com os princípios básicos do seu pensamento e da sua obra. Eles são completamente diferentes da autonomia heterogovernada, desta autonomia meramente técnica e operacional que nos convida a executar criativamente as políticas que já foram definidas. Agora, nós somos criativos e autônomos na execução; tudo que haveria de essencial já foi decidido heteronomamente. Nós somos agora autônomos para implementar... A palavra não é bonita: para executar, para operacionalizar as regras e as decisões heterônomas. Aqui está uma tensão que, de fato, é grande, e Freire ajuda, ajuda muito a compreendê-la. 
Ruth Pavan: Para finalizar, em toda a nossa entrevista, as questões abordadas têm a ver com a defesa de uma escola pública, democrática e participativa, portanto, contrária à lógica da mercantilização, que se baseia, entre outros, no gerencialismo, na competição, no produtivismo, na lógica puramente instrumental, como o senhor tão bem aponta em suas publicações, palestras e conferências. Em síntese, quais são os principais desafios de uma escola pública, democrática e participativa, e como o pensamento de Paulo Freire pode contribuir nesse processo?

Licínio C. Lima: Os desafios são muitos. No fundo, é como tornar a escola pública mais pública no sentido da persecução do interesse público, da diversidade social e cultural que hoje, por uma maior democratização do acesso à escola, coexiste na escola e relativamente à qual a organização escolar tem grandes dificuldades.

A questão da participação e da autonomia é também, possivelmente, o único caminho possível para a democratização da escola, no sentido de que não é possível afrontar os grandes desafios da diversidade social, cultural, étnica e religiosa que uma escola pública mais aberta em termos de acesso contempla, sem termos professores com o mínimo de capacidade de decisão, de decisão participada, com um projeto político educativo democrático, debatido. Isso se vê muito nas escolas portuguesas. Como é que os professores são hoje incapazes, na maior parte dos casos, de dar resposta pedagógica articulada, atempada, na hora, arriscando, tomando decisões na sala de aula, no plano pedagógico, educativo, comportamental.

$\mathrm{Na}$ verdade, os professores estão manietados, estão aprisionados por diretivas, por receios, por medos, por injunções, por ordens, pelo diretor, por um conjunto de mecanismos. Há aqui uma pedagogia aprisionada, uma prática pedagógica aprisionada no interior da sala de aula e que é incompatível com a resposta educativa e pedagógica, em tempo, no devido contexto, por parte do professor. O professor tem que ser um decisor. Se o professor se recusa a decidir, se tem medo de decidir, se tem medo de se expor, se não tem retaguarda do colegiado, do seu grupo de professores, da escola, da direção, eu diria, o professor sente-se solitário, sente-se perdido, sente-se amedrontado e, portanto, esse professor vai ser incapaz de dar resposta a esses grandes desafios da diversidade, de tudo aquilo que ocorre na sala de aula e que não é planeável, que não é previsível, mas que tem de ter resposta, individual ou coletiva.

Só a autonomia individual e coletiva do professor lhe pode dar instrumentos de ação passíveis de democratizar a pedagogia escolar, a relação pedagógica. É por isso que, no final da vida, Freire irá defender essas concepções participativas, a participação verdadeira como ingerência, uma coisa que ele diz já nos primeiros trabalhos. Ingerência, uma palavra forte. Nós até damos, em geral, 
uma conotação pejorativa à ingerência, mas ele quer acentuar esta participação política forte. Eu costumo brincar um pouco com as palavras. Na linha do próprio autor, a participação não significa participar na gerência dos outros; a participação é mais do que isso - é ingerência. Na verdade, não é participar do que já está estabelecido no quadro institucional, político, organizacional. Isso é simplesmente jogar o jogo a partir das definições, das regras do jogo, dos objetivos e do projeto político em que nós não participamos. Isso é heteronomia, são as regras dos outros. Autonomia não é isso. Autonomia é participar da própria definição das regras do jogo.

\section{REFERÊNCIAS}

LIMA, Licínio C. Escolarizando para uma educação crítica: a reinvenção das escolas como organizações democráticas. In: TEODORO, António; TORRES, Carlos Alberto (org.). Educação crítica e utopia: perspectivas para o século XXI. Porto: Afrontamentos, 2005. p. 19-31.

LIMA, Licínio C. Sobre a educação cultural e ético-política dos professores. Educar em Revista, Curitiba, n. 61, p. 143-156, set. 2016.

LIMA, Licínio C. Política e politicidade da educação: uma disciplina sobre Paulo Freire lecionada em Portugal. Revista Movimento, Niterói, ano 4, n. 7, p. 377-407, jul./dez. 2017.

Texto recebido em 17/06/2019.

Texto aprovado em 01/05/2020. 